\title{
Strength Difficulties Questionnaire (SDQ) Profile of Children with Sensorineural Hearing Loss: A Descriptive Study
}

\author{
Jeffrey Agung*, Yunias Setiawati, Nining Febryana
}

\author{
Child and Adolescent Psychiatrists, Psychiatry Department, Faculty of Medicine, Universitas \\ Airlangga / Dr. Soetomo Hospital, Surabaya, Indonesia \\ *Corresponding author details: Jeffrey Agung
}

\begin{abstract}
Purpose: The increasing number of hospital visits by children with sensorineural deafness needs attention. Apart from causing functional communication disruption, it is also initiating a psychopathological stressor that triggers mental health disorders such as emotional, depression, lack of self-confidence, and behavioral problems, which overall impact the quality of life of children in Indonesia's future. The aim of this study is to identify emotional and behavioral problems in sensorineural deaf children using the Strength Difficulties Questionnaire (SDQ).

Methods: This study used a descriptive observational research design. The subjects of this study were children with sensorineural deafness who visited the pediatric hearing center in Jala Puspa clinic, in Naval Hospital Dr. Ramelan Surabaya, in January 2021. The data was collected using the Strength Difficulties Questionnaire (SDQ) questionnaire. The data were analyzed descriptively.

Results: The respondents in this study were 50 sensorineural deaf children consisting of 27 boys and 23 girls. The results show that both children with sensorineural deafness who used a hearing aid or cochlear implants had a natural tendency to have emotional and behavioral problems, indicated by the difficulty subscale score. Borderline degrees of 20 (91\%) children using hearing aid and 15 (54\%) in children using cochlear implants (CI), on the power subscale indicated $11(50 \%)$ in children using hearing aid and $9(32 \%)$ in children taking CI.

Conclusion: Both sensorineural deaf children using hearing aids and cochlear implants tend to have emotional and behavioral problems.
\end{abstract}

Keywords: sensorineural deaf children; emotional and behavioral problems; preliminary studies.

\section{INTRODUCTION}

The growth and development of the organ of hearing function is a critical factor in the children's early life and their future. The hearing function is one of the vital tools as the primary medium in linguistic communication. WHO, 2018 estimates an increase to 466 million people with hearing loss which consists of $93 \%$ or about 432 million in adults and $7 \%$ or about 34 million in children.[1,2]

Hearing loss is the partial or total inability to hear sound in one or both ears. The severity is ranging from mild (20-39 $\mathrm{dB})$, moderate $(40-69 \mathrm{~dB})$ to severe $(70-89 \mathrm{~dB})$ and very severe ( $>90 \mathrm{~dB})$. Sensorineural hearing loss (SNHL) is a type of hearing loss with a poor prognosis and permanent damage due to failure of the nerves and other receptor organs to receive and transmit electrical signals of sound to the area of the brain where these electrical signals are perceived. The causes of sensorineural hearing loss include genetics, prenatal infection (TORCHS), prematurity or low birth weight (LBW < 1500 grams), ototoxic drugs, physical or acoustic trauma and neoplasms.[3] These conditions cause limitations and disabilities in children during their development and have an impact as a psychopathological stressor that triggers the behavioral mental disorders in the form of emotional problems, depression, anxiety, irritability, and accompanied by maladaptive behavior.

These conditions will affect the children's adaptability towards disturbances in daily life, and it impacts the quality of life of children in the future.[4,5]
Children with sensorineural deafness that are not treated with proper therapy may cause various mental health and behavioral problems later in life. A study based on interviews and medical records shows that children with hearing loss show psychopathological symptoms, in both internal and external, higher than children with normal hearing ability, with a tendency of internalizing symptoms between $4-10 \%$ and externalizing symptoms approximately $1 \%$. Stevenson et al. (2015) showed that the prevalence of internalizing symptom was $27 \%$, and externalization symptom was $18 \%$ in sensorineural deaf children.[6] A study shows that children with hearing aids showed a higher total SDQ score than children who used cochlear implants. It is important to know the emotional and behavioral problems in children with sensorineural hearing loss to detect their mental health disorders earlier and determine the further intervention steps.[7]

SDQ is a measuring tool to assess the tendency of emotional and behavioral problems. The SDQ consists of 25 items divided across five subscales.

The four subscales are included in the difficulty scale: emotional symptoms, conduct problem, hyperactivityinattention, and peer problem. The fifth subscale, the prosocial, is included in the strength scale group. Each SDQ subscale consists of five questionnaire items which each item is rated on a three-point scale, $0=$ not true, $1=$ somewhat or sometimes true, 2 = certainly true. 
The score of each subscale can be calculated by summing the scores of each relevant item on the subscale. The highest score of each subscale is 10 , and the lowest score is 0 . The interpretation of the SDQ results is that the higher the score on the difficulty subscale means there are problems in each subscale, while the lower the strength subscale indicates a problem with that subscale. The interpretation table of SDQ is shown below (Table 1).[6,8,9]

This study aims to assess emotional and behavioral problems using the Strength Difficulties Questionnaire (SDQ) instrument in schizophrenic sensorineural deaf children who visited the children hearing center, Jala Puspa clinic in Naval Hospital Dr. Ramelan Surabaya. The data distribution shown in the table consists of the demographic distribution of the sensorineural deaf children according to age, gender, duration of sensorineural deafness, using hearing aids or cochlear implants, and the assessment of emotional and behavioral problems using the SDQ. The study about the emotional issues and behavior profile of sensorineural deaf children has never been done before. We hope that our study can be used as a preliminary study for further research and improve the health services at the children hearing center, Jala Puspa clinic, Naval Hospital Dr. Ramelan Surabaya.

\section{METHODS}

This study is a descriptive observational design using SDQ questionnaire data on sensorineural hearing loss children who use hearing aids or cochlear implants. It is conducted in the children hearing center, Jala Puspa clinic, Naval Hospital Dr. Ramelan Surabaya, in January 2021. The total participant was 50 children that meet the inclusion criteria, which consist of 1) sensorineural hearing loss children 6-12 years old, 2) Use hearing aids and cochlear implants, and 3) No history of psychiatric disorders such as Autism Spectrum Disorder (ASD), Attention Deficit and Hyperactive Disorder (ADHD), Intellectual Disability (ID). This study aims to assess the emotional and behavioral problems in sensorineural deaf children to recognize early psychiatric problems in children with disabilities such as sensorineural deaf children and references for further comprehensive management. This study has been approved by Naval Hospital Dr. Ramelan Surabaya Ethics Committee.

\section{RESULTS}

The participant consisted of 50 sensorineural deaf children, 27 boys and 23 girls. Twenty-eight participants using cochlear implants, and 22 using hearing aids. The age range is from 6 to 12 years. The characteristic of the participants are shown in the following tables (Table 2).

From the respondents' data obtained, there were 24 (48\%) children in the age range of six to eight years, 16 (32\%) children in the age range of nine to ten years, and $10(20 \%)$ children in the age range of eleven to twelve years. The boys were $27(54 \%)$ children, while the girls were 23 (46\%). Twenty-two children (44\%) use hearing aids, and 28 (56\%) children use cochlear implants.

In difficulty subscale (Table 3), 15 (30\%) children were in normal condition, $35(70 \%)$ children were in the borderline criteria, and no children were in abnormal criteria according to the SDQ. In the age of six to eight years, there were $4(17 \%)$ children in normal condition, 20 (83\%) in the borderline range, and no children in the abnormal range.

At the age of nine to ten years, 7 (44\%) children were normal, $9(56 \%)$ children were borderline, and no children were in the abnormal range. Meanwhile, in the age of eleven to twelve years, 4 (40\%) children were in a normal assessment, and $6(60 \%)$ children were in a borderline range.
In the gender group, $22(81 \%)$ boys were within the borderline range, and $5(19 \%)$ boys were normal. While in the girls group, 13 (57\%) children were in borderline and 10 $(43 \%)$ were in the normal range. Most of the children who use hearing aids are in the borderline range $(20$ children (91\%) vs 2 (9\%) normal range children). Among cochlear implant users, 15 (54\%) children were borderline and 13 $(46 \%)$ in the normal range. None of the children was in abnormal ratings in either group.

In the assessments on the strength subscale (Table 4), ten children had an abnormal score of strength subscale while 20 children were in the borderline range. It should be noted because it is consisted of $60 \%$ of the total sample. In six to eight years, $9(56 \%)$ of 24 children had abnormal values , with $10(42 \%)$ children in the borderline range. In nine to ten years, $1(6 \%)$ of the 16 children were in the abnormal category, and 6 (38\%) children were borderline. No participants of age eleven to twelve years were included in the abnormal category. However, 4 (40\%) of them were included in borderline. In the boys group, 7 (20\%) children have abnormal scores and $9(33 \%)$ were borderline. While in the girls group, only 3 (13\%) out of 23 children were in the abnormal category, but 11 (48\%) children were borderline. Abnormal strength score was higher in children with hearing than children with cochlear implants. Data on children with hearing aids showed that $9(41 \%)$ children have abnormal total strength scores and $11(50 \%)$ in the borderline category. In children using cochlear implants, only $1(4 \%)$ child were in abnormal category, and 9 (32\%) children were in the borderline category on the strength subscale.

\section{DISCUSSION}

The results of the data distribution above show linearity with previous literature references and research studies that children with hearing loss shows psychopathology in the form of internalizing and externalizing symptoms compared to children without hearing loss.[10,11] The preliminary data above indicates that both children with sensorineural deafness who use a hearing aid or CI tend to experience emotional and behavioral problems, as indicated by borderline result in difficulty subscale of 20 (91\%) children who use a hearing aid and 15 (54\%) in children using cochlear implants (CI), while in the power subscale also shown borderline result in $11(50 \%)$ children using a hearing aid and $9(32 \%)$ in children with CI. The borderline result is lower in children with CI due to better sound stimulus process in children with CI.

However, the tendency for emotional and behavioral problems remains in both groups. A study showed that children with hearing loss showed psychopathological symptoms of internalizing and externalizing symptoms compared to children without hearing loss. $[12,13]$ Children using conventional hearing aids have a higher risk of psychopathology compared to children with CI. Conventional hearing aids bother children's communication ability during learning sessions, affect their academic achievement, and disrupt social interactions and function.[11] Meta-analysis study examining emotional and behavioral problems using the SDQ showed that children with hearing loss suffer from psychopathology disruption in the form of internalizing and externalizing symptoms. $[6,14]$

In terms of language, children with hearing loss generally have the following characteristics: 1) poor vocabulary, 2) difficulty understanding long sentences, 3) difficulty understanding metaphor phrases, 4) difficulty mastering rhythm and style of language.[8] Barriers to language development also cause barriers to intelligence.[15] 
Since intelligence development is influenced by learning experiences that involve hearing, the average intelligence of children with hearing loss was found lower than normal hearing children.[5] As explained above that sensorineural deafness is a physical and psychological stressor, the neuromodulators will stimulate stress hormones, starting from stimulation of the hypothalamic-pituitary axis (HPA) which activates the paraventricular nucleus cells of the hypothalamus to produce corticotropin-relational factor (CRF) then stimulates the pituitary to produce adrenocorticotropin hormone (ACTH) which will stimulate the adrenal cortex to produce cortisol and in the same time activated the sympathetic-adrenomedullary axis (SAM) that produces catecholamines (e.g. epinephrine). Both cortisol and catecholamines increase energy availability by stimulating the process of fat breakdown and conversion into ready-to-use energy and the transformation of glycogen to glucose and distribution via the blood vessels. The energy that has been processed will turn the organ into a "battle station" through an increase in blood vessel pressure which is responded by an enlargement of the heart muscle and high cardiac output. Exposure to physical stressors in several nuclei in the brain stem, medulla and spinal cord also stimulates PVN nucleus cells, nucleus tractus solitary (NTS) and dorsomedial hypothalamus (DMH), which will affect the structure of the brain in regulating autonomic function. SAM and HPA axis have a major role in regulating chemical mediators in the brain by projecting them throughout the brain and body, which later impact the regulation of emotions and behavior.[14,16-18]

Since stressor characteristics are persistent, specific, and last a long time, it can cause mechanical disruption of adaptation and homeostasis that continue to become a particular neurobiological series that causes adaptive malfunction and impact the emotional affection and behavior, resulting in emotional problems, depression, anxiety, irritability and maladaptive behavior. These conditions may affect the development of adaptation ability to daily life interruptions and impact the quality of life of children in the future. Another development that may be delayed was emotional and social aspects. $[4,19]$

A systematic review study shows that hearing loss, especially sensorineural deafness, will isolate the children from society, difficult to fully participated at school, work, neighbors, friends, even with family activity. This situation will inhibit the development of affection, emotions, and behavior of children with hearing loss resulting in feelings of inferiority, irritability and anger, anxiety, introversion, and fear. In the end, their personality and social development are less developed as people in general.[6,12,20] Early recognition of the emotional and behavioral problems in children with hearing loss is essential for early mental health diagnosis and intervention.[7] Management of patients should consist of pharmacology therapy and nonpharmacology therapy. The non-pharmacology treatment includes repetitive and continued social skills training. Modifying parenting or caregivers is also important to prevent further psychiatric problems in children with hearing loss.

\section{CONCLUSION}

Hearing is one of the critical senses for supporting language skills, including language development, speaking, and communication. Children with sensorineural deafness suffer from maldevelopment of speech and language in their early life, which may cause psychiatric problems, including

cognitive, psychological, and neuropsychopathological aspects later in life. The stress reaction triggered by the brain's neuromodulator system leads to a persistent and chronic psychiatric disorder.
Children with hearing loss have a high prevalence of psychiatric problems. Therefore, the management of children with hearing loss focuses on improving their hearing function and their psychiatric issues.

We hope that this research could be initial research about psychiatric problems in children with hearing loss. Further research is needed about the relationship of factors that affect psychiatric issues such as the age, duration of deafness, socioeconomic, parenting, and comorbidity of children with hearing loss.

Acknowledgements: JA conducted concepting, data collecting and analysis, and write the final manuscript. YS and NF helped in data analysis and article revision.

Ethics Approval: this study has been registered and approved by Naval Hospital Dr. Ramelan Surabaya Ethics Committee

Conflict of Interest: the authors have no conflict of interest to report

\section{Funding: none}

\section{REFERENCE}

[1] Adegbiji WA, Olajide GT, Olatoke F, Olajuyin AO, Olubi O, Ali A, et al. Preschool Children Hearing Impairment: Prevalence, Diagnosis and Management in a Developing Country. The International Tinnitus Journal 2018;22:60-5.

[2] WHO. WHO global estimates on prevalence of hearing loss Mortality and Burden of Diseases and Prevention of Blindness and Deafness. Mortality and Burden of Diseases and Prevention of Blindness and Deafness 2012.

[3] Novastuti CD, Wiyadi H. Sensorineural hearing loss pada anak. Jurnal THT-KL, Departemen SMF Ilmu Kedokteran Telinga-Hidung Dan Tenggorokan-Bedah Kepala Leher Fakultas Kedokteran Universitas Airlangga-RSUD Dr Soetomo 2016;9.

[4] Abbas Q. Prevalence of emotional disturbance in children with hearing impairment and intellectual disability. African Journal of Psychiatry (South Africa) 2016;19.

https://doi.org/10.4172/2378-5756.1000350.

[5] Boerrigter M, Vermeulen A, Marres H, Mylanus E, Langereis M. Frequencies of Behavioral Problems Reported by Parents and Teachers of HearingImpaired Children With Cochlear Implants. Frontiers in Psychology 2019;10:1591. https://doi.org/10.3389/FPSYG.2019.01591.

[6] Stevenson J, Kreppner J, Pimperton H, Worsfold S, Kennedy C. Emotional and behavioural difficulties in children and adolescents with hearing impairment: a systematic review and meta-analysis. European Child \& Adolescent Psychiatry 2015;24:477-96. https://doi.org/10.1007/S00787-015-0697-1.

[7] Nunes A, Silva C, Balen S, Souza D, Barbosa I. Prevalence of hearing impairment and associated factors in school-aged children and adolescents: a systematic review. Brazilian Journal of Otorhinolaryngology 2019;85:244-53. https://doi.org/10.1016/J.BJORL.2018.10.009. 
[8] Oktaviana M, Wimbarti S. Validasi Klinik Strenghts and Difficulties Questionnaire (SDQ) sebagai Instrumen Skrining Gangguan Tingkah Laku. Jurnal Psikologi 2014;41:101. https://doi.org/10.22146/JPSI.6961.

[9] Istiqomah I. Parameter Psikometri Alat Ukur Strengths and Difficulties Questionnaire (SDQ). Psympathic: Jurnal Ilmiah Psikologi 2017;4:251-64. https://doi.org/10.15575/PSY.V4I2.1756.

[10] Fiorillo CE, Rashidi V, Westgate PM, Jacobs JA, Bush ML, Studts CR. Assessment of Behavioral Problems in Children with Hearing Loss. Otology \& Neurotology 2017;38:1462.

https://doi.org/10.1097/MA0.0000000000001583.

[11] Bigler D, Burke K, Laureano N, Alfonso K, Jacobs J, Bush M. Assessment and Treatment of Behavioral Disorders in Children with Hearing Loss: A Systematic Review. Otolaryngol Head Neck Surg 2019;160:36-48. https://doi.org/10.1177/0194599818797598.

[12] Theunissen SCPM, Rieffe C, Soede W, Briaire JJ, Ketelaar L, Kouwenberg M, et al. Symptoms of psychopathology in hearing-impaired children. Ear and Hearing 2015;36:e190-8. https://doi.org/10.1097/AUD.0000000000000147.

[13] Laugen NJ, Jacobsen KH, Rieffe C, Wichstrøm L. Predictors of Psychosocial Outcomes in Hard-ofHearing Preschool Children. The Journal of Deaf Studies and Deaf Education 2016;21:259-67. https://doi.org/10.1093/DEAFED/ENW005.
[14] Wang H, Wang Y, Hu Y. Emotional Understanding in Children with A Cochlear Implant. Journal of Deaf Studies and Deaf Education 2019;24:65-73. https://doi.org/10.1093/DEAFED/ENY031.

[15] Nelson C, Bruce SM. Children who are deaf/hard of hearing with disabilities: Paths to language and literacy. Education Sciences 2019;9:134. https://doi.org/10.3390/EDUCSCI9020134.

[16] Ms. G. Deepika, Ms. Rajeswari. H. Impact of Neurotransmitters on Health through Emotion. International Journal of Indian Psychology 2016;3. https://doi.org/10.25215/0302.145.

[17] Godoy LD, Rossignoli MT, Delfino-Pereira P, GarciaCairasco N, de Lima Umeoka EH. A Comprehensive Overview on Stress Neurobiology: Basic Concepts and Clinical Implications. Frontiers in Behavioral Neuroscience 2018;0:127. https://doi.org/10.3389/FNBEH.2018.00127.

[18] Chauduri A. Pathophysiology of Stress: A Review. International Journal of Research and Review 2019;6:199-213.

[19] Pathak KP, Gaire T. Psychiatric Disorders with Hearing and Speech Impairment in Nepalese Children. Acta Scientific Medical Sciences 2019;3:52-4. https://doi.org/10.31080/ASMS.2019.03.0344.

[20] Idstad M, Tambs K, Aarhus L, Engdahl BL. Childhood sensorineural hearing loss and adult mental health up to 43 years later: results from the HUNT study. BMC Public Health 2019 19:1 2019;19:1-9. https://doi.org/10.1186/S12889-019-6449-2. 
TABLE 1: Strength and difficulty questionnaire (SDQ) score classification

\begin{tabular}{|l|c|c|c|}
\hline \multicolumn{1}{|c|}{ Scales } & Normal & Borderline & Abnormal \\
\hline Total difficulty score & $0-15$ & $16-19$ & $20-40$ \\
\hline Emotional symptom score & $0-5$ & 6 & $7-10$ \\
\hline Conduct problem score & $0-3$ & 5 & $5-10$ \\
\hline Hyperactivity score & $0-5$ & 6 & $7-10$ \\
\hline Peer problem score & $0-3$ & $4-5$ & $6-10$ \\
\hline Prosocial behavior score & $6-10$ & 5 & $0-4$ \\
\hline
\end{tabular}

TABLE 2: Characteristics of the 50 patients included in the study

\begin{tabular}{|c|c|}
\hline \multicolumn{1}{|c|}{ Characteristics } & N (\%) \\
\hline Age (years) & $24(48 \%)$ \\
\hline $6-8$ & $16(32 \%)$ \\
\hline $9-10$ & $10(20 \%)$ \\
\hline $11-12$ & \\
\hline Gender & $27(54 \%)$ \\
\hline Boy & $23(46 \%)$ \\
\hline Girl & \\
\hline Hearing aid/cochlear implant & $22(44 \%)$ \\
\hline Hearing aid & $28(56 \%)$ \\
\hline Cochlear Implant &
\end{tabular}

TABLE 3: Total difficulty score results

\begin{tabular}{|c|c|c|c|}
\hline & Normal & Borderline & Abnormal \\
\hline \multicolumn{4}{|l|}{ Age (years) } \\
\hline $6-8$ & $4(17 \%)$ & $20(83 \%)$ & $0(0 \%)$ \\
\hline $9-10$ & $7(44 \%)$ & $9(56 \%)$ & $0(0 \%)$ \\
\hline $11-12$ & $4(40 \%)$ & $6(60 \%)$ & $0(0 \%)$ \\
\hline \multicolumn{4}{|l|}{ Gender } \\
\hline Boy & $5(19 \%)$ & $22(81 \%)$ & $0(0 \%)$ \\
\hline Girl & $10(43 \%)$ & $13(57 \%)$ & $0(0 \%)$ \\
\hline \multicolumn{4}{|c|}{ Hearing aid/cochlear implant } \\
\hline Hearing aid & $2(9 \%)$ & $20(91 \%)$ & $0(0 \%)$ \\
\hline Cochlear Implant & $13(46 \%)$ & $15(54 \%)$ & $0(0 \%)$ \\
\hline Total & $15(30 \%)$ & 35 (70\%) & $0(0 \%)$ \\
\hline
\end{tabular}

